\title{
Leader-member Exchange and Organizational Citizenship Behavior: A New Perspective from Perceived Insider Status and Chinese Traditionality
}

\author{
(C) Higher Education Press and Springer-Verlag 2010
}

\begin{abstract}
Although much research has been done on the relationship between leader-member exchange (LMX) and organizational citizenship behavior (OCB), little attention has been paid to the mechanism underpinning the relationship. Based on a sample of 214 supervisor-subordinate dyads from indigenous family business in China, this paper examines the mechanism by which LMX affects OCB, especially the mediating role of perceived insider status and the moderating role of Chinese traditionality. Structural equation modeling results show that: (1) LMX is positively related to OCB, and (2) perceived insider status fully mediates the relationship between LMX and OCB. Hierarchical regression results further reveal that Chinese traditionality moderates the effect of LMX on perceived insider status.
\end{abstract}

Keywords leader-member exchange, perceived insider status, Chinese traditionality, organizational citizenship behavior

Translated from Guanli Shijie 管理世界 (Management World), 2009, (1): 97-107

Lin Wang $(\bowtie)$

Lingnan College, Sun Yat-sen University, Guangzhou 510275, China

E-mail: tony-wanglin@139.com

Xiaoping Chu

Lingnan College, Sun Yat-sen University, Guangzhou 510275, China

E-mail: lnscxp@mail.sysu.edu.cn

Jing Ni

Lingnan College, Sun Yat-sen University, Guangzhou 510275, China

E-mail: jiayuang@163.com 


\section{Introduction}

Leader-member exchange (LMX) has become the focus of leadership research over the past 30 years, since firstly proposed by Grean, Dansereau and Minami (1972). Before the establishment of the LMX theory, it had been agreed that superiors treat each of their subordinates equally (Northhouse, 2000). However, the LMX theory argues that supervisors develop differentiated relationships with their subordinates (Grean and Cashman, 1975; Grean, 1976). Although much research on the relationship between LMX and organizational citizenship behavior (OCB) has been done, study that examines the mechanisms underpinning the relationship is still lacking. Accordingly, the mechanism behind the relationship still remains unclear. In addition, as many researchers have pointed out, owing to the cultural difference between China and western countries, the leadership and management mode in Chinese firms is also different from that of in western firms (Hofstede, 1980; Redding, 1990; Cheng, 1995; Westwood, 1997). Considering the lack of relevant study in the Chinese context, this article aims to explore how and why Chinese LMX affects the OCB of subordinates.

In the domain of organizational research, most of the studies on the relationship between LMX and OCB are based on the social exchange theory (Blau, 1964), which argue that leaders shall give more trust and support to their subordinates to ensure high quality LMX (Liden, Sparrowe and Wayne, 1997). In an attempt to fulfill the reciprocity obligations, subordinates will demonstrate more OCB (Gerstner and Day, 1997). Researchers both at home and abroad have shown that the cognition and mood of subordinates are important mediator of leader behaviors (e.g., Chen, Jia, Li, Song and Zhang, 2006; Chen and Aryee, 2007). Neglecting these important mediators has made the effect mechanism of Chinese leader behavior remain unclear (Chou, Cheng, Farh, Jen and Huang, 2006). Therefore, starting with the cognition and mood of the subordinates can provide a good approach to the question "how to lead efficiently" (Wu and Cheng, 2003). As a result, in order to better understand the internal effect mechanism of LMX in the Chinese text, the current study regards the effect of LMX on OCB as a process of self-categorization (Turner et al., 1987), namely, high-quality LMX will promote members' OCB through enhancing their self-concepts. Perceived insider status refers to "the extent to which an individual employee perceives himself or herself as an insider within a particular organization" (Stamper and Masterson, 2002), which nicely reflects the cognitive dimension of self-concept (Chen and Aryee, 2007). Thus, the current study takes the employees' perceived insider status as a mediating variable. 
In addition, the cultural value orientation of employees shall not be neglected when analyzing the effect mechanism of LMX in the Chinese context. That is because people with different cultural values usually hold different viewpoints towards the same thing (Huntington, 1997). As observed by many researchers, along with the progress of the Chinese society, people's submission to authority has already been weakened to a certain extent (Cheng et al., 2003). Accordingly, employee's attitude towards deference to authority may be an important moderating variable in the relationship between employee's efficiency and organizational behavior (Farh, Hackett and Liang, 2007). In the meantime, relevant research has already revealed that the effect of LMX may be different owing to different situational factors, especially different authority value orientation of individuals (Hui, Lee and Rousseau, 2004). Therefore, though not be confirmed by empirical study, it is reasonable to deduce that employees' authority value orientation will moderate the relationship between LMX and perceived insider status. Chinese traditionality refers to an individual's endorsement of hierarchical role relationships as defined by the five cardinal relationships (called wu-lun) in Confucianism (i.e., emperor-subject, father-son, husband-wife, older brother-younger brother, and friend-friend), reflecting the cultural dimension of employees' submission to authority (Farh, Earle and Lin, 1997). Thus, this paper takes the employees' Chinese traditionality as the moderating variable.

Drawing on the sample of supervisor-subordinate dyads from indigenous family business in China, the current study aims to probe into the mediating role of perceived insider status and the moderating role of Chinese traditionality in the relationship of LMX and OCB. Against the backdrop of China's transitional culture and economy, such an attempt from a brand-new perspective (i.e., the perspective of self-categorization), we believe, will be of great theoretical and practical importance to Chinese family business.

\subsection{LMX and OCB}

From the beginning of the 1980 s, the very proposal of the concept OCB has drawn wide attention. OCB is important in that it can help the organization operate efficiently and further win its competitive advantage (Farh et al., 1997). Per Organ (1988), OCB refers to "individual behavior that is discretionary, not directly or explicitly recognized by the formal reward system, and that in the aggregate promotes the effective functioning of the organization". However, whether the OCB theory developed in the western context applicable to Chinese firms? Farh, Zhong and Organ (2004) conducted research on this problem in the Chinese context and found a 10-dimension structure of OCB, consisting of five 
dimensions similar to that of the western context (i.e., taking initiative, helping coworkers, voice, group activity participation, promoting company image) and five dimensions different from that of the western context (i.e., self-training, social welfare participation, protecting and saving company resources, keeping workplace clean and interpersonal harmony). Following their line, this article will measure OCB based on these ten dimensions.

Originated in the Vertical Dyad Linkage (VDL) (Grean and Cashman, 1975; Grean, 1976), the core of LMX is to refute the opinion of "leader treats all the employees with a relatively consistent style" (average leadership style, ALS); thereby LMX transfers the research center from simplex leaders to mutual relationship between leaders and members. According to the LMX theory, leaders develop differentiated relationships with subordinates ranging from low to high quality and adopt different management modes depending on the quality of exchange relationships. According to the social exchange theory (Blau, 1964), in high-quality LMX relationship, more trust exists between leaders and followers, and leaders appeal to the higher-order social needs of followers by getting them to place collective interests over short-term personal gratification (Graen and Uhl-Bien, 1995). In the meantime, in order to feedback the trust and support from the leader, employees will make more effort that beyond explicit role requirements to fulfill the reciprocity obligations. Because OCB represents a reciprocal exchange that is not only unspecified and weakly time-bound, but also promotes the group welfare of enterprise. Therefore, it becomes the first choice for the members in high-quality LMX to be a "good citizen". Much empirical research has indicated that LMX has a positive correlation with OCB, regardless of different organizations and cultures. For example, Liden and Graen (1980) proved that members in high-quality LMX relationship will receive more support, job discretionary and trust from the leader, and will exhibit higher OCB. Similarly, Hui, Law and Hackett (2004) also suggested that the LMX is significantly positively related to OCB. However, extant research has paid little attention to the special features of Chinese family business. As has been pointed out, employees in Chinese family business are more likely to be seen as loyal to their supervisor rather than to the organization (Cheng, 1995). We therefore deduce that LMX shall have a significant positive prediction for OCB in Chinese family business. Accordingly, we hypothesize:

H1 LMX is positively related to OCB.

\subsection{LMX and Perceived Insider Status}

In the field of organizational management, with the growing interest in the concept of organizational identity (Hsu and Cheng, 2003; Ravasi and Rekom, 
2003), perceived insider status of the employees has drawn more attention from researchers and practitioners alike (Masterson and Stamper, 2003). Perceived insider status refers to "the extent to which an individual employee perceives him or herself as an insider within a particular organization" (Stamper and Masterson, 2002). Masterson and Stamper (2003) pointed out that although three are many dimensions referring to employee cognition of employee-organization relationship, perceived insider status focuses on employees' belonging with the organization. In subsequent research, some researchers also emphasize that perceived insider status is an important dimension of employees' self-concept (Chen et al., 2007). Meanwhile, leaders in Chinese family business tend to divide the employees into in-group member or out-group member (Yang, 1995), then further group the employees with characteristics of in-group member as insiders, or otherwise outsiders (Cheng, 1995). Thus, employees' perceived insider status in Chinese family business is more likely to indicate their perception of himself or herself as an insider.

Previous research has indicated that LMX can enhance employees' perceived insider status (Chen et al., 2007). According to the LMX theory, leader will establish different relationships with employees and the quality of these relationships reflects employees' different identities as in-group members or out-group members (Graen and Uhl-Blen., 1995). Accordingly, leader will provide different inducement for different types of employees, such as more training, promotion, trust and delegation for the in-group members. In this way, the quality of the relationship between employees and leaders affect the perceived insider status of employees significantly (Stamper and Masterson, 2002). For this aspect, Chen and Aryee (2007) confirmed that high-quality LMX can strengthen the perceived insider status of employees. They also proved that delegation which is the key characteristic of high-quality LMX has a significantly positive correlation with perceived insider status of the employees.

In all, in high-quality LMX, employee will gain more inducements such as trust, support and delegation because of their identity of insiders, which also offer them the signals that they have obtained "personal space" in the organization and been accepted by the organization. However, Hofstede's cross-culture research claimed that there is higher power distance in China than in western nations (Hofstede, 1980). Owing to such cultural difference, political difference, economic difference and the difference of legal norms, it will still need further verification whether LMX rooted in the western culture can affect perceived insider status of employees in Chinese family business. Accordingly, we hypothesize:

H2 LMX is positively related to perceived insider status. 


\subsection{Mediating Mechanism}

Perceived insider status can promote employees' OCB due to the following reasons: once employees realize that they are insiders of the organization, they tend to regard themselves as the citizen of the organization and accept the relevant responsibilities. Moreover, they will positively participate in the activities beyond explicit role requirements and refuse the activities that may damage the operation of the organization. On the contrary, when the employees realize that they are outsiders of the organization, they will resist or reduce OCB without being punished because the organization never expects the outsiders to implement OCB (Graham, 1991; Stamper et al., 2002). Much research has indicated that perceived insider status has a significantly positive correlation with OCB (Stamper et al., 2002; Chen et al., 2007). This conclusion has been supported by some Chinese scholars in their study on Chinese family business (Cheng, 1995; Jiang and Cheng, 2003). However, their research on the relationship between perceived insider status and OCB in Chinese family enterprise mainly centralizes on theoretical analysis. Relevant empirical study is serious lacking. Accordingly, we hypothesize:

H3 Perceived insider status is positively related to OCB.

Although much research has studied the relationship between LMX and OCB, little empirical research has focused on the effect mechanism of LMX on OCB (Chen et al., 2007). Chen etc. (2007) chose 238 supervisor-subordinate dyads from two firms in Zhejiang to investigate the mediating role of subordinates' feedback-seeking behavior in the link of LMX and subordinates' performance. Results indicate that negative feedback-seeking behavior partially mediates the links between LMX and subordinates' in-role performance. Among the existing literature, Chen et al's (2007) study is a rare case that has paid attention to the mediating mechanism between LMX and performance. However, they also neglected the effect mechanism of LMX on OCB. In addition, just as what they pointed out as a limitation in their article, the samples of their research were drawn solely from two Chinese limited corporations that had been restructured from state-owned enterprises. Therefore, whether this result can be applied to other organizations with different cultural background or different types remain debatable. Wang, Xin and Tsui (2006) indicated that under the condition of transitional economy, firms with different ownerships coexist in China, so it still needs further exploration whether leader's behavior may have different effect mechanism in different types of firms.

It has been pointed out that not only the president of Chinese family business will classify employees into different groups (Cheng, 1995), so do the employees 
themselves. Subordinates will also categorize themselves according to their own relationship with their supervisor (Lai et al., 2006). As a cross-culture phenomenon, self-categorization mainly emphasizes self-concept, representing the psychological process of the individual to define themselves as a member of the group, which promote group behavior, such as initiative cooperation and altruism, etc. (Turner et al., 1987). However, the connotation and practice of self-categorization are deeply affected by cultural context and organizational context. For example, Lai, Lin and Huang (2006) found that as for Chinese society, it is not generally emphasized to make self-definition based on individual feature (height, face and personality, etc.), but based on the identification of relationship, or in other words, making self-definition according to the connection of interpersonal relationship. Therefore, in Chinese firms, especially for family business, it is the unique characteristic of relational self in Chinese society that makes the relationship between the employees and important others (such as his or her supervisor) a great impact on the employees' self-concept development (Huang, 2000). As perceived insider status is an important dimension of self-concept (Chen et al., 2007), it is not hard to deduce that in Chinese family business, LMX will affect employees' OCB through enhancing perceived insider status. Accordingly, we hypothesize:

H4 Perceived insider status mediates the relationship between LMX and OCB.

\subsection{Moderating Mechanism}

Individual differences in traditionality will affect the magnitude of relationships between LMX and perceived insider status. Pioneered by Yang, Yu and Yeh (1989), Chinese traditionality is identified as be composed of five dimensions, including submission to authority, filial piety and ancestor worship, conservatism and endurance, fatalism and defensiveness, and male dominance. Later, Farh, Earle and Lin (1997) introduced these dimensions into the field of organizational management research. However, they mainly focused on the dimension of submission to authority and emphasizing an individual's endorsement of hierarchical role relationships as defined by the five cardinal relationships ( $w u$ lun) in Confucianism. Based on the sample of Taiwan employees, they found that traditionality significantly moderates the relationship between organizational justice and employees' OCB. The subsequent research of Hui, Lee and Rousseau (2004) based on a sample of 605 supervisor-subordinate dyads from mainland of China also indicates a moderating effect of traditionality between LMX and employees' OCB. Their results also revealed that for the employees with low traditionality, there will be a strong correlation between the LMX and OCB, but as for the employees with high traditionality, the correlation is weak. More 
recently, Farh, Hackett and Liang (2007) explored the moderating effect of traditionality in the relationship between perceived organizational support and OCB through investigating the matching sample of 163 supervisor-subordinate dyads from mainland of China. The result shows that the relationship is stronger for the employees with low traditionality; and weaker for the employees with high traditionality.

According to the theory of cultural self-representation, employee's authority value orientation shall affect the performance through moderating the relationship between the management practice and employee' self-concept (Chen et al., 2007). However, research on this moderating effect of Chinese tradition between LMX and perceived insider status has never been approved by western researchers, not to mention any empirical study conducted in the context of Chinese culture. Under a collectivistic culture like China, LMX usually implies unequal exchange relationship (Hofstede and Bond, 1988). For employees who are more traditional, they usually have expressive relationships with their leaders based on societal expectations of roles which have already been preexisted. On the contrary, while for employees with low traditionality, their attitudes and behaviors towards the leaders are usually determined by the extent of equality and reciprocity in the process of exchange (Farh et al., 1997). Therefore, in Chinese family business, high-quality LMX will not enhance perceived insider status of the employees with high traditionality; while significantly affect that of the employees with low traditionality. Accordingly, we hypothesize:

H5 Chinese traditionality moderates the relationship between LMX and perceived insider status in such a way that the relationship is stronger for those lower, rather than higher, in traditionality.

\section{Methods}

\subsection{Research Setting, Participants and Procedures}

In this study, the survey was conducted from July 2008 to October 2008. Participating firms share the following features. Firstly, it must be an indigenous family business in China. Secondly, each participating firm must have more than 30 employees. Thirdly, the participating firm must have existed more than one year. Finally, each participating employee must have at least an immediate supervisor. Data were collected from 21 firms located in Guangdong Province, especially in urban Guangzhou, Dongguan and Shunde City, where family business relatively converged. Most of the participating firms were from the home appliance manufacturing or service industries. 
To avoid common method variance and self-report bias, we used the data obtained from supervisor-subordinate dyads. The whole survey process included the following steps: Firstly, we randomly selected 2 or 3 middle or top managers in each participating firm, each of whom then further randomly selected 4-9 immediate subordinates, with an average selection number of 6 . Secondly, we wrote the subordinate's name on the supervisor's questionnaire in pencil and asked the supervisor to assess this subordinate's OCB. The completed questionnaires were returned sealed in envelopes to the researchers. Thirdly, a coding system was used to match supervisor ratings to subordinate responses, so the matching subordinate's questionnaire containing code numbers was distributed to subordinate. The completed questionnaires were also returned sealed in envelopes to the researchers. Finally, we bound these questionnaires up in pair, and further conducted a series of job as questionnaire selection, questionnaire coding, data input and data analysis.

Supervisor questionnaires were distributed to 54 supervisors, and subordinate questionnaires were distributed to 310 immediate subordinates of these supervisors. A total of 256 completed questionnaires were received from subordinates and 45 from supervisors representing a response rate of $83.3 \%$ and $82.5 \%$, respectively. After deleting records of unmatched supervisor-subordinate pairs, a total of 214 supervisor-subordinate dyads remained and constituted the final sample for this study. Of the subordinate sample, $47.2 \%$ were men, $80.9 \%$ were between 21 and 30 years old, $66.8 \%$ had 1-3 years organizational tenure, and $67.7 \%$ received vocational school education or above.

\subsection{Measures}

All measures were originally constructed in English. To assure the validity of the constructs in the Chinese context, we made certain adjustments with the items. Firstly, to assure equivalence of the measures in the Chinese and the English versions of the survey instrument, we performed a standard translation and back-translation procedure (Brislin, 1980). Secondly, the Chinese version was subsequently pilot-tested on employees from 4 participating indigenous family business which were not included in the final sample. 180 employees were invited and 132 completed surveys (an 88\% response rate). On the basis of these data, exploratory factor analysis and reliability testing showed a favorable result with all construct's Cronbach's alpha above 0.80. Finally, the meaning and expression of each item was further discussed in a symposium. Responses to all the measures were made on a 5-point Likert-type scale anchored by 1 (strongly disagree) to 5 (strongly agree). 


\subsubsection{Measure of LMX}

To measure LMX, we used the 7 items scale developed by Graen and Uhlbien (1995). This short form of LMX scale has been widely adopted in LMX research (cf. Schriesheim and Gardiner, 1992). Sample items include, "My leader knows my potential" and "My working relationship with my supervisor is very productive". The Cronbach's alpha of this scale in the present study was 0.862 .

\subsubsection{Measure of Perceived Insider Status}

We used the 6-item scale developed by Stamper and Masterson (2002) to measure perceived insider status. This scale has previously been used in the Chinese context and showed an acceptable reliability with a Cronbach's alpha of 0.80 (Chen et al., 2007). Sample item are, "I feel I am an 'insider' in my work organization", and "My work organization makes me believe that I am included in it". Cronbach's alpha for this scale in our study was 0.871 .

\subsubsection{Measure of $\mathrm{OCB}$}

We used the 9-item scale developed by Farh, Zhong and Organ (2004) to measure employee's OCB. This scale has previously been used in the Chinese context and showed an acceptable reliability with a Cronbach's alpha of 0.75 (altruism), 0.84 (voice), and 0.83 (conscientiousness) (Farh, Hhackett and Liang, 1997). Sample items include, "Actively raises suggestions to improve work procedures or processes" and "Initiates assistance to coworkers who have a heavy workload". In our study, Cronbach's alphas were 0.835 (altruism), 0.885 (voice), and 0.827 (conscientiousness), respectively.

\subsubsection{Measure of Chinese Traditionality}

We used the five-item scale developed by Farh, Earley and Lin (1997) to measure Chinese traditionality. This scale has previously been used broadly in the Chinese context (Farh, Hhackett and Liang, 1997). Sample items include, "The best way to avoid mistakes is to follow the instructions of senior persons", and "Children should respect those people who are respected by their parents". The scale's Cronbach's alpha was 0.725 .

\subsubsection{Control Variables}

Previous research on OCB has shown that employee's demographic characteristics, 
such as age, education, gender and tenure, usually comprised the primary control variables (Farh et al., 1997). Therefore, we controlled for these four demographic variables that might potentially influence the results. Tenure was measured by number of years. Gender was dummy-coded as 1, "male," and 0, "female." Age had eight categories: 20 or under, 21-25, 26-30, 31-35, 36-40, 41-45, 46-50, and over 50. Education had five categories: middle school or under, high school or technical secondary school, vocational school, university, and graduate school.

\section{Results}

\subsection{Confirmatory Factor Analysis}

According to the methods of Kelloway (1998) and Wang et al. (2005), the current research randomly averaged the items of relevant variables' measure to form three indicators (Wang et al., 2005; Kelloway, 1998). ${ }^{1}$ In this way, the seven indicators of LMX were combined into three new indicators, the six indicators of perceived insider status three new indicators, and the five indicators of Chinese traditionality three new indicators. Then we used the newly formed indicators of LMX, perceived insider status, Chinese traditionality and OCB to carry out confirmatory factor analysis. The result shows that the four-factor model fits the data better than other nested models (see Table 1), indicating that the four variables show a good discriminant validity, so that we can make further analysis using structural equitation.

Table 1 Results of Confirmatory Factor Analysis $(n=214)$

\begin{tabular}{|c|c|c|c|c|c|c|c|}
\hline Model & Factors & $X^{2}$ & $d f$ & RMSEA & GFI & CFI & NNFI \\
\hline $\begin{array}{l}\text { Baseline } \\
\text { model } 1\end{array}$ & Four factors & 89.25 & 48 & 0.064 & 0.93 & 0.97 & 0.96 \\
\hline Model 2 & $\begin{array}{l}\text { Three factors: LMX and OCB are } \\
\text { combined into one factor }\end{array}$ & 306.14 & 51 & 0.153 & 0.81 & 0.85 & 0.80 \\
\hline Model 3 & $\begin{array}{l}\text { Three factors: LMX and PIS are } \\
\text { combined into one factor }\end{array}$ & 263.91 & 51 & 0.140 & 0.83 & 0.87 & 0.84 \\
\hline Model 4 & $\begin{array}{l}\text { Three factors: LMX and CT are } \\
\text { combined into one factor }\end{array}$ & 278.28 & 51 & 0.145 & 0.82 & 0.86 & 0.82 \\
\hline Model 5 & $\begin{array}{l}\text { Three factors: CT and PIS are } \\
\text { combined into one factor }\end{array}$ & 200.98 & 51 & 0.118 & 0.86 & 0.89 & 0.86 \\
\hline Model 6 & $\begin{array}{l}\text { Three factors: } \mathrm{CT} \text { and OCB are } \\
\text { combined into one factor }\end{array}$ & 278.78 & 51 & 0.145 & 0.82 & 0.85 & 0.81 \\
\hline
\end{tabular}

(To be continued)

\footnotetext{
${ }^{1}$ According to Kelloway (1998), this method can avoid the non-identification of the model caused by the fact that there are many indicators for the latent variables in structural model.
} 


\begin{tabular}{|c|c|c|c|c|c|c|c|}
\hline \multicolumn{8}{|c|}{ (Continued) } \\
\hline Model & Factors & $X^{2}$ & $d f$ & RMSEA & GFI & CFI & NNFI \\
\hline Model 7 & $\begin{array}{l}\text { Three factors: OCB and PIS are } \\
\text { combined into one factor }\end{array}$ & 263.51 & 51 & 0.140 & 0.83 & 0.87 & 0.83 \\
\hline Model 8 & $\begin{array}{l}\text { Two factors: LMX, OCB and PIS } \\
\text { are combined into one factor }\end{array}$ & 432.22 & 53 & 0.183 & 0.75 & 0.77 & 0.72 \\
\hline Model 9 & $\begin{array}{l}\text { Two factors: } \mathrm{LMX}, \mathrm{OCB} \text { and } \mathrm{CT} \\
\text { are combined into one factor }\end{array}$ & 498.57 & 53 & 0.199 & 0.72 & 0.74 & 0.68 \\
\hline $\begin{array}{l}\text { Model } \\
10\end{array}$ & $\begin{array}{l}\text { Two factors: OCB, CT and PIS are } \\
\text { combined into one factor }\end{array}$ & 371.88 & 53 & 0.168 & 0.77 & 0.79 & 0.74 \\
\hline $\begin{array}{l}\text { Model } \\
11\end{array}$ & $\begin{array}{l}\text { One factor: all the four factors } \\
\text { (LMX, OCB, CT, PIS) are } \\
\text { combined into one factor }\end{array}$ & 540.36 & 54 & 0.206 & 0.70 & 0.70 & 0.63 \\
\hline
\end{tabular}

Note: LMX means leader-member exchange, OCB means organizational citzien behavior, PIS means perceived insider status, CT means Chinese traditionality.

\subsection{Descriptive Statistics}

Table 2 shows the means, standard deviations, and correlations among the variables in this study. LMX correlates significantly $(p<0.01)$ with perceived insider status, Chinese traditionality and OCB $(r=0.454, r=0.129$ and $r=0.229$, respectively), perceived insider status correlates significantly $(p<0.01)$ with Chinese traditionality and OCB ( $r=0.389$ and $r=0.379$, respectively), and Chinese traditionality correlates significantly $(p<0.01)$ with OCB $(r=0.151)$. Besides, the regression analysis indicates that LMX has significantly positive relationships with perceived insider status and OCB while controlling for age, gender, education and tenure. Perceived insider status has significantly positive relationships with OCB. Therefore, hypothesis 1,2 and 3 are supported.

Table 2 Means, Standard Deviations, and Correlations Among Variables

\begin{tabular}{lccccc}
\hline \multicolumn{1}{c}{ Variales } & Mean & S.D. & 1 & 2 & 3 \\
\hline LMX & 3.82 & 0.614 & & & \\
perceived insider status & 3.79 & 0.620 & $0.454^{* *}$ & & \\
Chinese traditionality & 3.52 & 0.647 & $0.129^{* *}$ & $0.389^{* *}$ & \\
OCB & 3.78 & 0.656 & $0.229^{* *}$ & $0.379^{* *}$ & $0.151^{* *}$ \\
\hline
\end{tabular}

Note: $\quad * *$ indicates significant at 0.01 level, $n=214$.

Table 3 presents the means, standard deviations and correlations after adopting the three new indicators of LMX, perceived insider status and OCB. Structural equation model demonstrates unique advantages when analyzing the mutual relationships of latent variables with a few indicators (Baron and Kenny, 1986). So we test Hypothesis 4 from establishing structural equation model with the 
three variables in Table 3.

Table 3 Means, Standard Deviations, and Correlations

\begin{tabular}{|c|c|c|c|c|c|c|c|c|c|c|}
\hline Variales & Mean & S.D. & & 2 & 3 & 4 & 5 & 6 & 7 & 8 \\
\hline \multicolumn{11}{|l|}{ LMX } \\
\hline 1. indicator 1 & 3.75 & 0.666 & & & & & & & & \\
\hline 2. indicator 2 & 3.68 & 0.835 & $0.518 * *$ & & & & & & & \\
\hline 3. indicator 3 & 4.06 & 0.686 & $0.672 * *$ & $0.579 * *$ & & & & & & \\
\hline \multicolumn{11}{|l|}{$\begin{array}{l}\text { Perceived insider } \\
\text { status }\end{array}$} \\
\hline 1. indicator 1 & 3.89 & 0.688 & $0.434 * *$ & $0.216 * *$ & $0.461 * *$ & & & & & \\
\hline 2. indicator 2 & 3.92 & 0.698 & $0.399 * *$ & $0.173 * *$ & $0.432 * *$ & $0.748 * *$ & & & & \\
\hline 3. indicator 3 & 3.56 & 0.718 & $0.369 * *$ & $0.227 * *$ & $0.383 * *$ & $0.640 * *$ & $0.633 * *$ & & & \\
\hline \multicolumn{11}{|l|}{ OCB } \\
\hline 1. Altruism & 3.90 & 0.717 & $0.239 * *$ & $0.134 * *$ & $0.176^{* *}$ & $0.276 * *$ & $0.325 * *$ & $0.362 * *$ & & \\
\hline 2. Voice & 3.52 & 0.883 & $0.173 * *$ & 0.064 & 0.091 & $0.211 * *$ & $0.219 * *$ & $0.287 * *$ & $0.560 * *$ & \\
\hline 3. conscientiousness & 3.86 & 0.797 & $0.257 * *$ & $0.155^{* *}$ & 0.095 & $0.238^{* *}$ & $0.240 * *$ & $0.319 * *$ & $0.634 * *$ & $0.435 * *$ \\
\hline
\end{tabular}

Note: The three indicators of LMX, perceived insider status, and OCB are formed randomly.

** indicates significant at 0.01 level, $n=214$.

\subsection{Structural Model Analysis of Mediating Effect}

According to Baron and Kenny (1986), to test the mediation of perceived insider status between the relationship of LMX and OCB, we shall first verify that LMX is significantly related to perceived insider status and $\mathrm{OCB}$, and that perceived insider status also is significantly related to OCB. The significant positive relationships among these three factors (i.e. $\mathrm{H} 1, \mathrm{H} 2$ and $\mathrm{H} 3$ ) have already been supported above. Subsequently, we load perceived insider status into the relationship model of LMX and OCB to check the change in the relationship. If the original relationship between LMX and OCB disappeared, then perceived insider status is fully mediating the relationship between LMX and OCB; if the relationship is still significant but weakened, then perceived insider status is partially mediating the relationship between LMX and OCB.

On the basis of correlation matrix in Table 3, we firstly establish model 1, representing a direct path model from $\mathrm{LMX}$ to $\mathrm{OCB}$, then model 2 representing a partial mediating path model, and finally model 3 representing a full mediating model. As shown in Table 4, all three models (i.e. Model 1, Model 2 and Model 3) have a good data fitting, but the fit indices reveals that Model 2 and Model 3 are significantly improved compared to Model 1. Thus, we accept Model 2 and Model 3.

Then, we make further comparison of the change in the relationship between LMX and OCB., with no mediation of perceived insider status (Model 1), LMX 
is positively and significantly related $(p<0.01)$ to OCB $(\beta=0.26)$. When we specify the mediating path of perceived insider status, as in Model 3, the beta coefficient for LMX is reduced $(\beta=0.02, p>0.05)$. Therefore, when adding perceived insider status, the relevant relationship of LMX and OCB almost disappears, Thus Model 3 is accepted.

In summary, the results shown in Table 2 and Table 4 support Hypothesis 4: perceived insider status fully mediates the relationship between LMX and OCB. Fig. 1 shows the path coefficient at the significance of 0.05 . The effect of LMX for the perceived insider status is significant $(\beta=0.57, p<0.05)$; And that of perceived insider status for OCB is also significant $(\beta=0.43, p<0.05)$.

Table 4 Comparison of Structural Equation Models

\begin{tabular}{lrrrrrrr}
\hline Model and Structure & $X^{2}$ & d.f. & $\mathrm{X}^{2} /$ d.f. & EMSEA & GFI & CFI & NNFI \\
\hline 1. Direct path model: $\mathrm{LMX} \rightarrow \mathrm{OCB}$ & 13.30 & 8 & 1.66 & 0.056 & 0.98 & 0.99 & 0.98 \\
$\begin{array}{l}\text { 2. Partially mediation model: } \\
\text { LMX } \rightarrow \text { PIS } \rightarrow \text { OCB and LMX } \rightarrow \text { OCB }\end{array}$ & 36.83 & 24 & 1.53 & 0.050 & 0.96 & 0.99 & 0.98 \\
$\begin{array}{l}\text { 3. Fully mediation model: } \\
\quad \text { LMX } \rightarrow \text { PIS } \rightarrow \text { OCB }\end{array}$ & 36.92 & 25 & 1.48 & 0.047 & 0.96 & 0.99 & 0.98 \\
& & & & & & & \\
\hline
\end{tabular}

Note: LMX means leader-member exchange, OCB means organizational citzien behavior, PIS means perceived insider status.

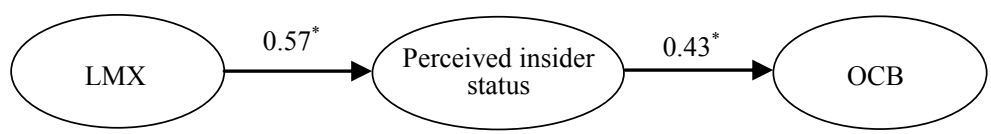

Fig. 1 Results of Structural Equation Modeling on the Mediating Effect of Perceived Insider Status

Note: * denotes significant at 0.05 level.

\subsection{Moderating Effects of Chinese Traditionality}

Table 5 shows the regression result of the moderation of Chinese traditionality between the relationship of LMX and perceived insider status. As stated in H5, Chinese traditionality does have a significant moderating effect on the relationship between LMX and perceived insider status $(\beta=-0.186, p<0.05)$. Following Aiken and West's proposal (1991), we define the high Chinese traditionality and low Chinese traditionality as $+/-1$ standard deviation from the mean, and then establish the regression equation of LMX and perceived insider status respectively. As shown in Fig. 2, LMX is positively related to perceived insider status for employees with low traditionality $(\beta=0.503, p<0.05)$, while as for employees with high traditionality, the relation between LMX and perceived insider status is very weak $(\beta=0.018, p>0.05)$. Thus, H5 is fully supported. 
Table 5 Results of Regression Analysis for Moderation by Traditionality

\begin{tabular}{|c|c|c|c|}
\hline \multirow[b]{2}{*}{ Variables } & $\mathrm{M}_{1}$ & $\mathrm{M}_{2}$ & $\mathrm{M}_{3}$ \\
\hline & \multicolumn{3}{|c|}{ Perceived insider status } \\
\hline & $\beta_{1}$ & $\beta_{2}$ & $\beta_{3}$ \\
\hline \multicolumn{4}{|l|}{ Step 1: Controls } \\
\hline Gender & 0.081 & -0.012 & -0.001 \\
\hline Age & $0.138^{*}$ & 0.079 & 0.090 \\
\hline Education & -0.055 & -0.055 & -0.042 \\
\hline Tenure & -0.069 & 0.004 & -0.002 \\
\hline Adjusted $R^{2}$ & 0.011 & & \\
\hline$F$ & $1.582 *$ & & \\
\hline \multicolumn{4}{|l|}{ Step 2: Main effects } \\
\hline Traditionality & & $0.328^{*}$ & $0.360 *$ \\
\hline LMX & & $0.421^{*}$ & $0.405^{*}$ \\
\hline Adjusted $R^{2}$ & & 0.316 & \\
\hline$\Delta R^{2}$ & & 0.302 & \\
\hline$F$ & & $17.257^{*}$ & \\
\hline \multicolumn{4}{|l|}{ Step 3: Moderating effect } \\
\hline LMX $\times$ Traditionality & & & $-0.186^{*}$ \\
\hline Adjusted $\mathrm{R}^{2}$ & & & 0.347 \\
\hline$\Delta R^{2}$ & & & 0.031 \\
\hline$F$ & & & $17.026^{*}$ \\
\hline
\end{tabular}

Note: * indicates significant at 0.05 level, $n=214$.

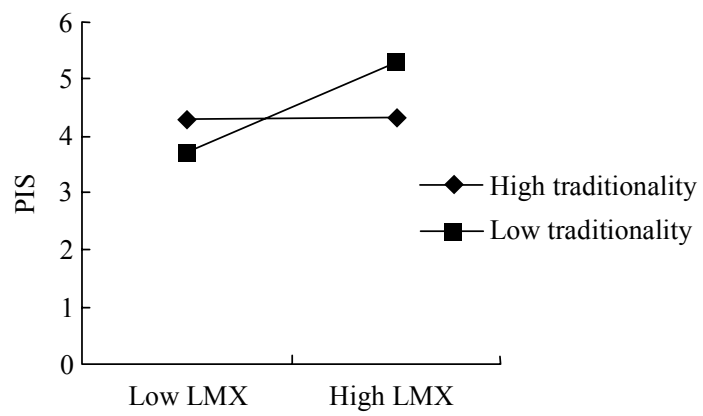

Fig. 2 LMX and Perceived Insider Status by Traditionality

\section{Conclusion and Discussion}

\subsection{Conclusion}

The current study aims to investigate the effect mechanism of LMX on OCB in Chinese family business, especially the mediating role of perceived insider status and moderating role of Chinese traditionlaity. To begin with, the paper proposes 
five hypotheses based on a review of extant literature. Because all the measurement of the constucts comes from western literature, in order to guarantee the validity of these measurements in the Chinese context, we revise some items and retest the discriminant validity of variables. The current study shows that (1) LMX is positively related to employees' OCB (support $\mathrm{H} 1$ ), and perceived insider status (support $\mathrm{H} 2$ ); (2) perceived insider status has a significantly positive relationship with OCB (support H3); and (3) perceived insider status is fully mediating in relationship of LMX and OCB (support H4); and (4) LMX is significantly related to perceived insider status for employees with low traditionality, while the effect is very weak as for employees with high traditionality (support H5).

\subsection{Implication}

Much research on the relationship between LMX and OCB is based on social exchange theory (Blau, 1964), emphasizing that LMX has a directly positive prediction effect on OCB (Liden, Sparrowe and Wayne, 1997; Wakabayashi, Chen and Graen, 2005). Consistent with these studies, our findings suggest the relationship between LMX and OCB is positive and significant. What is more, our research shows that as for Chinese family business, perceived insider status fully mediates the relationship between LMX and OCB. In other words, high-quality LMX can indirectly affect OCB through enhancing positive perception of insider status. Thus the effect process of LMX to OCB is not only a type of social exchange, but also a process of self-categorization. This perspective deepens people's understanding of intrinsic effect mechanism between LMX and OCB. Moreover, it has already been generally agreed that organizational context and cultural context can not be neglected in the research on organizational behavior (Rousseau and Fried, 2001).

Firstly, from the cultural perspective, in the west culture where individualism prevails, people's perception of self-concept focuses on integrating behavior to make himself or herself different from others, and usually view himself or herself as a unique entity. On the contrary, in Chinese culture where collectivism prevails, what self-concept reflects is no longer an independent entity, but mainly a self in relation with others, namely, the perception of self-concept is enhanced through relation with important others. Secondly, from the perspective of organizational context, different from other types of organizations, family business' owner or manager usually takes the father-like role, who takes good care of his/her employees but at the same time may also have "absolute authority" (Farh and Cheng, 2000). Thus, in the family business, high-quality LMX indicates that there are not only formal employment relationships, but also tight psychological contract relationship between leader and employees. The "strong relationship" with leaders enhances employee's self-concept perception 
in the family business, which further improves the effort-accomplishment expectancies, the intrinsic valence of effort and the intrinsic valence of goal accomplishment of the employees, so as to encourage employees to exhibit more OCB. In addition, as for employees who self-categorization as insiders, they usually share the same traits with the organization, and these traits will further engender a sense of belonging and identification with the organization, so as to make them willing to cooperate with the organization, take altruistic behaviors, take the initiative and carry out other citizen behavior.

Consistent with other studies (Hui et al., 2004; Chen et al., 2007), our findings also suggest that the effect of LMX may be changed owing to different value orientation of the employees. To be precise, the current study suggests that Chinese traditionality significantly moderates the relationship between LMX and perceived insider status. Possible explanation might be that the message employees accept from outside information useful to their self-concept (Tajfel, 1982), while the cultural value orientation generally determines the meaning of management practice for individuals, and also provides the evaluation criterion for "whether a management practice is helpful for individual's perception of self-concept ". Specifically, leaders of Chinese family business will classify employees into insiders and outsiders according to employee' different level of honesty and talent, and according to whether the employee has a close relation with him/her. Based on this judgment, a leader will provide varied level of inducement to each employee to make him/her one of the insiders (Cheng, 1995). However, not every employee that is classified as an insider and is granted with more inducement by the leader in family business generates the perceived insider status. Likewise, those who are classified as outsider may also experience perceived insider status because individual's authority value orientation varies. Although compared with western nations, Chinese society has a relative high power distance (Hofstede, 1980), yet the dimension of "submission to authority" has already been changed in Chinese family business (Farh and Cheng, 2000). As for the employees with high traditionality in Chinese family business, they tend to accept high power distance and are easy to accept the different role relationships with their leaders, so they are willing to comply with the arrangement from the leader and perform the in-role behavior as a subordinate, but not willing to take on more job responsibilities. Thus, the quality of exchange relationship will not affect their perceived insider status. As for the employees with low traditionality in family business, they tend to accept lower power distance and are easy to accept the reciprocal exchange relationships with their leader, so they will pay more attention to the equality of the exchange with their leader. Besides, they usually have a good awareness as an agent, focus on the need of self-realization, and expect to take on more job responsibilities. 
Therefore, in high quality LMX, employees with low traditionality will get more job autonomy, delegation and trust from their leaders, and these inducements will further enhance their perceived insider status.

The current study has significant managerial implications. Although several Chinese researchers have made certain research on the relationship between LMX and OCB, there is still no research about why and how LMX in Chinese family business affect OCB. As OCB is important for a firms' smooth operation and is conducive to improving a firms' competence and competitive advantage, so the managerial implications of this study include helping leaders of Chinese family business to motivate their employees to exhibit more OCB. According to the result of this study, firstly, leaders shall develop good exchange relationships with their employees. There are many ways to do this, such as helping solve problems employees encountered at work, realizing their potential, caring for their daily life, and building a good work relationship. All of these will drive employees make extra efforts voluntarily in order to feedback the support and trust from leaders, so as to exhibit more OCB. Secondly, leaders shall be good at helping the employees to create the feeling that they are insiders. Leaders should offer more inducement signals to their employees, such as bringing them into contact with more critical information, offering them with more autonomy, flexibility, opportunity and rewards, etc,.

Meanwhile, an organization shall also conduct relevant training and assessment projects to promote employees' perceived insider status. What is more important is that for the employees with different authority value orientation, the effect of LMX on perceived insider status is also different. Therefore, leaders shall know their subordinates' cultural orientations of Chinese traditionality. Compared with the employees with high traditionality, the leader shall rather provide more opportunities and delegations to the employees with low traditioality, so as to enhance these employees' perceived insider status and finally promote their OCB. At the same time, relevant training shall be conducted to weaken the cultural orientations of the employees with high Chinese traditionality in order to make them take more job responsibilities and exhibit more OCB. In addition, family business shall further build its core value and management institution in order to enhance its prestige construction, so as to shift employees' authority orientation from their superiors (that is to say, obedient to an individual) to the firm's vision and norms. The construction of institutional authority will not only improve the employees' orientation of high traditionality, but will also promote family business' stability and sustainability.

\subsection{Limitation and Future Research Direction}

This article has several important limitations. The first one has something to do 
with the cross-sectional design of this article. Although we suggest that LMX affects OCB through perceived insider status, it takes time for the effect to function. Because of cross-section design, even if our findings are consistent with the theoretical hypotheses, other conclusions can not be excluded. Therefore, future research that employs a longitudinal design may be better able to ascertain the causal basis of the relationships examined in this study (although the adoption of multi-source data, namely supervisor-subordinate dyads, has solved the problems caused by common method variance to some extent).

A second limitation is the selection of the sample. As noted, our data are solely collected from indigenous family business in Guangdong. Whether our findings can be applied to family business in other regions of China and to other types of organizations remains to be verified.

Future research of LMX and the work outcomes of employees can be enriched from two aspects. Firstly, more mediators shall be used to explore the mechanisms underlying the relationship between LMX and job satisfaction, organizational commitment, turnover intention, etc. Secondly, the moderating mechanism in the relationship between LMX and perceived insider status shall be further enriched. The current study only explores the moderating mechanism of employee's value orientation from the perspective of traditionality, further study should encourage efforts to develop other variables (such as power distance) to analyze the effect conditions and application scope of LMX on perceived insider status.

Acknowledgements This work is supported by the National Natural Science Foundation of China (No. 70872112). We also thank the reviewers of this paper, who offer us insightful feedback and suggestions.

\section{References}

Aiken L S, West S G (1991). Multiple regression: Testing and interpreting interactions. Thousand Oaks, CA: Sage

Baron R M, Kenny D A (1986). The moderator-mediator variable distinction in social psychological research: Conceptual, strategic and statistical considerations. Journal of Personality and Social Psychology, 51: 1173-1182

Blau P M (1964). Exchange and Power in Social Life. New York: Wiley

Brislin R W (1986). Translation and content analysis of oral and written material. In: Triandis H C, Berry J W (eds.), Handbook of Cross-cultural Psychology, Vol. 2. Boston, MA: Allyn \& Bacon, 389-444

Chen Z X, Aryee S (2007). Delegation and employee work outcomes: An examination of the cultural context of mediating processes in China. Academy of Management Journal, 50(1): 226-238

Chen Z G, Lam W, Zhong J A (2007). Leader-member exchange and member performance: A 
new look at individual-level negative feedback-seeking behavior and team-level empowerment climate. Journal of Applied Psychology, 92(1): 202-212

Erdogan B, Enders J (2007). Support from the top: Supervisors' perceived organizational support as a moderator of leader-member exchange to satisfaction and performance relationships. Journal of Applied Psychology, 92(2): 321-330

Farh J L, Earle P C, Lin S C (1997). Impetus for action: A cultural analysis of justice and organizational citizenship behavior in Chinese society. Administrative Science Quarterly, 42: 421-444

Farh J L, Hhackett R D, Liang J (2007). Individual-level cultural values as moderators of perceived organization supper-employee outcome relationships in China: Comparing the effects of power distance and traditionality. The Academy of Management Journal, 50(3): $715-729$

Farh J L, Zhong C B, Organ D W (2004). Organizational citizenship behavior in the people's republic of China. Organization Science, 15: 241-253

Gerstner C R, Day DV(1997). Meta-analytic review of leader-member exchange theory: Correlates and construct issues. Journal of Applied Psychology, 82: 827-844

Graen G (1976). Role making processes within complex organization. In: Dunnette M D (ed.), Handbook of Industrial and Organizational Psychology. Chicago: Rand McNally, $1201-1245$

Graen G, Dansereau F, Minami T (1972). Dysfunctional leadership styles. Organizational Behavior and Human Performance, 7: 216-236

Graen G B, Cashman J (1975). A role-making model of leadership in formal organizations: A developmental approach. In: Hunt J G \& Larson L L (eds.), Leadership Frontiers. Kent State University Press, 143-166

Graen G B, Uhl-Blen M (1995) Development of leader-member exchange (LMX) theory of leadership over 25 years: Applying a multi-level multi-domain perspective. Leadership Quarterly, 6: 219-247

Graham, J W (1991). An essay on organizational citizenship behavior. Employee Responsibilities and Rights Journal, 4: 249-270

Hackett R D, Farh J L, Song L J, Lapierre L M (2003). LMX and organizational citizenship behavior: Examining the links within and across Western and Chinese samples. In: Graen $\mathrm{G}$ B (ed.), Dealing with Diversity. Charlotte, NC: Information Age Publishing, 219-263

Hamilton G G (1984). Patriarchalism in imperial China and Western Europe: A revision of weber's sociology of domination. Theory and Society, 13: 393-426

Hofstede G H (1980). Culture's consequences: International differences in work-related values. Beverly Hills, CA: Sage

Hofstede G H, Bond M H (1988). The Confucius connection: From cultural roots to economic growth. Organizational Dynamics, 14: 5-39

Hui C, Lee C, Rousseau D M (2004). Employment relationships in China: Do workers relate to the organization or to people. Organization Science, 15(2): 232-240

Kelloway K (1998). Lisrel for Structural Equation Modeling: A Researcher's Guide. Thousand Oaks: Sage Publications

Liden R C, Sparrowe R T, Wayne S J (1997). Leader-member exchange theory: The past and potential for the future. Research in Personnel and Human Resource Management, 15: $47-119$

Masterson S S, Stamper C L (2003). Perceived organizational membership: An aggregate framework representing the employee-organization relationship. Journal of Organizational Behavior, 24: 473-490 
Northhouse P G (2000). Leadership: Theory and Practice. Thousand Oaks, CA: Sage

Organ D W (1988). Organizational Citizenship Behavior: The Good Soldier Syndrome. Lexington, MA: Lexington Books

Piccolo R F, Colquitt J A (2006). Transformational leadership and job behaviors: The mediating role of core job characteristics. Academy of Management Journal, 49(2): 327-340

Ravasi D, Van Rekom J (2003). Key issues in organizational identity and identification theory. Corporate Reputation Review, 6(2): 1-15

Redding S G (1990). The Spirit of Chinese Capitalism. New York: Walter de Gruyter

Rousseau D M, Fried Y (2001). Location, location, location: Contextualizing organizational research. Journal of Applied Psychology, 75: 246-257

Stamper C L, Masterson S S (2002). Insider or outsider? How employee perceptions of insider status affect their work behavior. Journal of Organizational Behavior, 23: 875-894

Tajfel H (1982). Social Identity and Intergroup Relations. Cambridge: Cambridge University Press

Turner J C, Hogg M A, Oakes P J, Reicher S D, Wetherell M S (1987). Rediscovering the social group: A self-categorization. Oxford, UK: Blackwell

Wakabayashi M, Chen, Z, Graen G B (2004). The global Asian way: Managerial efficacy profile (MEP) and LMX relationship in Asia. In: Graen G B (ed.), LMX Leadership: The Series: New Frontiers of Leadership, Vol. 2. Greenwich, CT: Information Age Publishing, $121-137$

Wang H, Law K S, Hackett R D, Wang D, Chen Z (2005). Leader-member exchange as a mediator of the relationship between transformational leadership and followers' performance and organizational citizenship behavior. Academy of Management Journal, 48(3): 420-432

Westwood R (1997). Harmony and patriarchy: The cultural basis for paternalistic headship among the overseas Chinese. Organization Studies, 18(3): 445-480

陈永霞, 贾良定, 李超平, 宋继文, 张君君 (Chen Yongxia, Jia Liangding, Li Chaoping, Song Jiwen, Zhang Junjun) (2006). 变革型领导、心理授权与员工的组织承诺：中国情景下的实证研究 (Transformational leadership, psychological empowerment and organizational commitment of employees: An empirical study in Chinese context). 管理世界, (1): 96-105

樊景立, 郑伯埙 (Farh Jiing-Lih Larry, Cheng Bor-shiuan) (2000). 华人组织的家长式领导: 一 项文化观点的分析 (Paternalistic leadership in Chinese organization: A Cultural Analysis). 本土心理学研究, (13): 127-180

黄光国 (Hwang Kwang-Kuo). 社会心理学的本土化 (Localization of social psychology). 国立 台湾大学末发表论文

姜定宇, 郑伯埙 (Jiang Ding-Yu, Cheng Bor-shiuan) (2003). 组织忠诚、组织承诺及组织公民行 为 (Organizational loyalty, organizational commitment and organizational citizen behavior). In: 组织行为研究在台湾：三十年回顾与展望. 台北：桂冠图书出版社, 115-152

赖志超, 林纯安, 黄国隆 (Lai Zhichao, Lin Chunan and Huang Kuo-Long) (2006). 组织认定的 竞争优势 (The competitive advantageof organizational identity). In: 华人组织行为议题、作法 及出版 (The issue, practice and publication of Chinese organizational behavior). 台北：华泰 文化事业股份有限公司, 324-363

吴宗佑，郑伯埙 (Wu Zongyou, Cheng Bor-shiuan) (2003). 组织情绪 (Organizational Emotion). In: 组织行为研究在台湾 (Organizational Behavior Study in Taiwan). 台湾：实业 文化出版公司, 153-187

徐玮伶, 郑伯埙 (Hsu Wei-Ling, Cheng Bor-shiuan) (2003). 组织认定与企业伦理效益 (Organizational identity and business ethics). 应用心理研究, (20): 115-138 
杨国枢 (Yang Kuo-shu) (1988). 中国人与自然、他人、自我的关系 (The relation of Chinese people with nature, other people and self). In: 中国人：观念与行为(Chinese People: Concept and Behavior). 台北：台北巨流出版社, 9-23

杨国枢 (Yang Kuo-shu) (1995). 家族化历程、泛家族主义及组织管理 (Family experience, pan-familism and organizational management). In: 海峡两案组织文化暨人力资源管理研讨会 论文集 (Essays of Seminar of Human Resource Management for Cross-strait Organizational Culture). 台北：信义文化基金会, 19-60

杨国枢，余安邦，叶明华 (Yang Kuo-shu, Yu An-bang, Yeh Minghua) (1989). 中国人的个人传 统性与现代性：概念与测量 (Chinese individual traditionality and modernity: Construct definition and measurement). In: 中国人心理与行为 (The Psychology and Behavior of Chinese People). 台湾：桂冠图书出版公司, 329-376

郑伯埙 (Cheng Bor-shiuan) (1995). 差序格局与华人组织行为 (Pattern of difference and Chinese organizational behavior). 本土心理学研究, (3): 214-219

郑伯埙, 周丽芳, 黄敏萍, 焚景立, 彭泗清 (Cheng Bor-shiuan, Chou Li-fang, Huang Min-ping, Farh Jiing-Lih Larry, Peng Siqing) (2003). 家长式领导的三元模式: 中国大陆企业组织的证据 (Tri-mode of paternalistic leadership: Evidence of enterprise organization in China mainland). 本土心理学研究期刊, (19): 209-252

周丽芳, 郑伯埙, 㚞景立, 任金刚, 黄敏萍 (Chou Li-fang, Cheng Bor-shiuan, Farh Jiing-Lih Larry, Jen Chin-kang, Huang Min-ping) (2006). 家长式领导 (Paternalistic leadership). In: 华人组织行为议题、作法及出版 (The issue, practice and publication of Chinese organizational behavior ). 台北：华泰文化事业股份有限公司, 46-82 